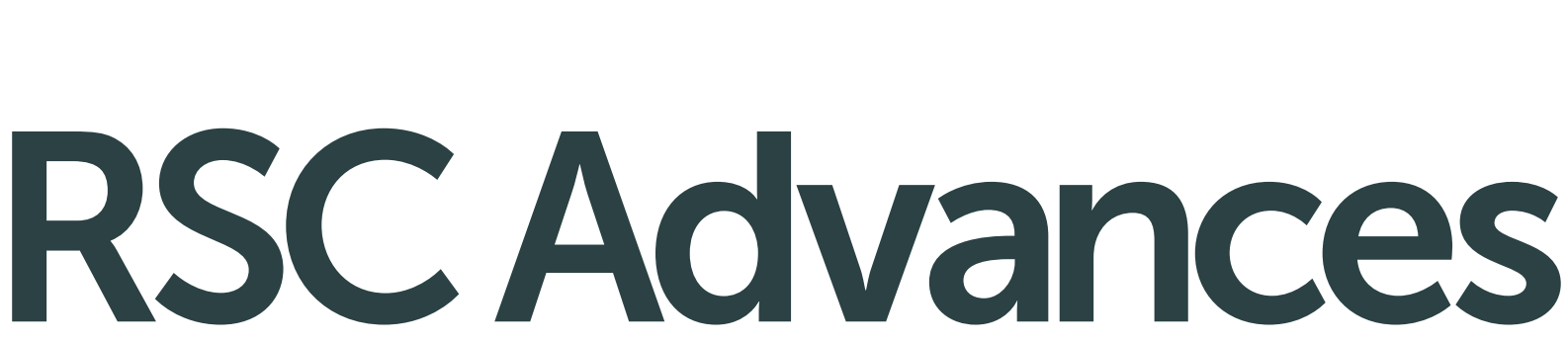

This article can be cited before page numbers have been issued, to do this please use: R. D. S. Alvim, F.

C. D. A. Lima, V. M. Sánchez, T. F. Headen, E. S. Boek and C. Rodrigues Miranda, RSC Adv., 2016, DOI:
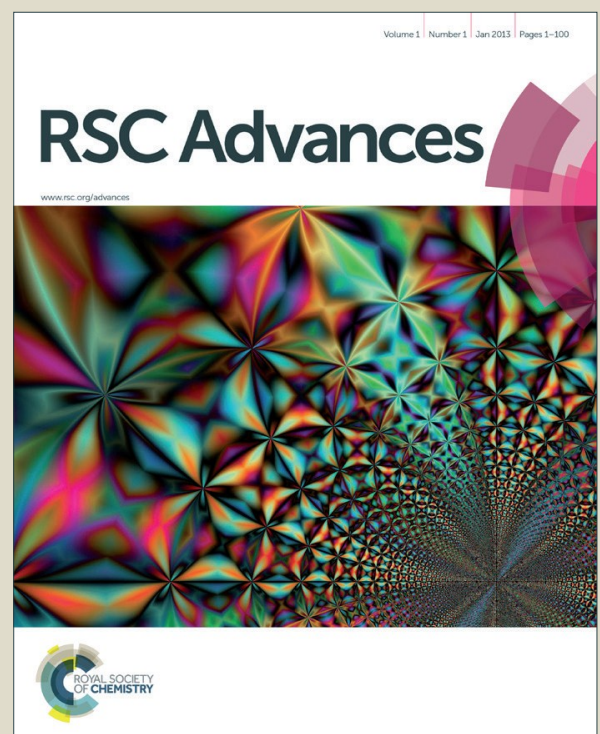

This is an Accepted Manuscript, which has been through the Royal Society of Chemistry peer review process and has been accepted for publication.

Accepted Manuscripts are published online shortly after acceptance, before technical editing, formatting and proof reading. Using this free service, authors can make their results available to the community, in citable form, before we publish the edited article. This Accepted Manuscript will be replaced by the edited, formatted and paginated article as soon as this is available.

You can find more information about Accepted Manuscripts in the Information for Authors.

Please note that technical editing may introduce minor changes to the text and/or graphics, which may alter content. The journal's standard Terms \& Conditions and the Ethical guidelines still apply. In no event shall the Royal Society of Chemistry be held responsible for any errors or omissions in this Accepted Manuscript or any consequences arising from the use of any information it contains. 


\title{
Adsorption of Asphaltenes on the Calcite (10.4) Surface by First-Principles Calculations
}

\author{
Raphael S. Alvim ${ }^{1,2}$, Filipe C. D. A. Lima², Verónica M. Sánchez ${ }^{1,3}$, \\ Thomas F. Headen ${ }^{4}$, Edo S. Boek ${ }^{5}$ and Caetano R. Miranda ${ }^{1,2 *}$ \\ ${ }^{1}$ Centro de Ciências Naturais e Humanas, Universidade Federal do ABC \\ Santo André, SP, 09210-580, Brazil \\ ${ }^{2}$ Departamento de Física dos Materiais e Mecânica, Universidade de São \\ Paulo, São Paulo, SP, 05508-090, Brazil \\ ${ }^{3}$ CSC, CONICET, Godoy Cruz 2390, 1425, Buenos Aires, Argentina \\ ${ }^{4}$ ISIS Neutron and Muon Source, Rutherford Appleton Laboratory, Harwell \\ Campus, Didcot, UK \\ ${ }^{5}$ Department of Chemistry, University of Cambridge, UK
}

\section{*cmiranda@if.usp.br}

\begin{abstract}
Asphaltenes play a key role on the oil production and exploration from natural reservoirs. In carbonate reservoirs, the calcite (10.4) surface retains asphaltenes. However, the aggregate structure and deposition processes are not fully understood. By first-principles calculations based on density-functional theory (DFT) with van der Waals (vdW) dispersion, we studied the adsorption of asphaltene, resin and resinasphaltene dimer molecular models on the $\mathrm{CaCO}_{3}$ surface in the presence of water and toluene dielectric environment. These large molecules impose a challenging description at electronic level. Our calculations indicate that there is steric hindering for the effective interaction of the aromatic region of the asphaltene on the calcite surface. However, the aliphatic chains with sulphide groups can play a significant role on the adsorption process and its availability to receive electronic charge density from the surface. Accordingly, the preferential LUMO localized in the aromatic region of the asphaltene may also allow the adsorption on the calcite surface by $\pi-\pi$ stacking. The resin molecule tends to be firstly trapped in the dimer formation with the
\end{abstract}


asphaltene, whereas a significant intramolecular charge rearrangement due to the heteroatoms is necessary to increase the $\pi-\pi$ stacking. For the dimer, the adsorbed form of the asphaltene favors more available electronic states to increase the likelihood of nanoaggregation. For this reason, changes on the continuum dielectric constant only had a minor effect on the calculated adsorption energies. Experimental works related to oil-water interface in presence of toluene show similar behavior of asphaltene adsorption. Our studies indicate that nanoaggregates are grown through resin and the calcite (10.4) surface selectively adsorbs the less polar asphaltenes from oil. 


\section{1- INTRODUCTION}

Asphaltenes are the macromolecular part of natural crude oil, defined by its insolubility in n-heptane and solubility in aromatic solvents such as toluene ${ }^{1-4}$. The molecules aggregate in good solvents forming $\sim 10 \mathrm{~nm}$ sized aggregates ${ }^{1-3}$. Asphaltene molecules have a relatively high molecular weight and are heteroatom-rich. They are the densest part of the oil with polar and non-polar groups giving some amphiphilic character. Furthermore, these compounds possess the ability to aggregate and adsorb to oil-water (hydrophobic-hydrophilic) interfaces to stabilize water-in-oil emulsions even at low concentrations.

The presence of high concentrations of asphaltene aggregates at the reservoir bottom can provide more complex upgrading technologies of many types of byproducts in the refining of heavy crude oils, such as the bitumen ${ }^{5-7}$, or yielding a lighter crude oil. Furthermore, some precipitating agents for asphaltenes, such as high-pressure reservoir gases, light paraffins and resins, may cause the partial or complete blockage of flow in the recovery and movement of petroleum through pipes, causing problems in the well and extraction facilities. For this reason, many structural features of these organic compounds have been extensively studied ${ }^{4,8-11}$.

Mainly due to their chemical composition, including a polyaromatic and polycyclic ring containing heteroatoms (N, O, S and metals), asphaltene molecules are susceptible to intermolecular forces responsible for their strong propensity to selfassociate, form aggregates and to adsorb on mineral surfaces of rocks ${ }^{11,12}$. In this context, resin molecules may play an important role in bridging the gap between the solubility of asphaltenes in polar and non-polar oils.

The resins consist of molecules of intermediate polarity similar to asphaltenes, differing by a reduced number of aromatic structures. They may be regarded as an important component for stabilizing asphaltenes due to the solubility of the asphaltenes with greater polarity and the non-polar moieties in the saturated oil matrix $^{13}$. These forces of attraction are mainly acid-base interactions, hydrogen bonds by the presence of water, coordination complexes, $\pi-\pi$ stacking and van der Waals $(\mathrm{vdW})$ interactions in hydrophobic regions ${ }^{3,14}$. The $\pi-\pi$ stacking is the most dominant force for asphaltene aggregation. This type of interaction could be inhibited in adsorption on the rock surface because of significant steric hindrance. 
Minerals are able to retain asphaltenes, and therefore play an important role in the development of enhanced oil recovery (EOR) operations, mainly in natural reservoir rocks ${ }^{15-18}$. Even in the absence of water, asphaltene adsorption on the mineral surfaces is driven by polar interaction, surface precipitation and H-bond formation ${ }^{17,18}$. The adsorption process produces marked changes in the wettability of the solid and reduces oil production from the reservoir ${ }^{3,19-22}$.

Compared to the bare mineral surface, González et al ${ }^{19}$ observed an increase of the contact angle in the mineral-water-toluene solution interface for asphaltenecovered surfaces, such as calcite. On the other hand, for low asphaltene concentrations in toluene, there was a decrease of the contact angle despite the adsorption of asphaltene on the mineral surface and the consequent purification of the organic solvent. An earlier study ${ }^{20}$ shows the increase of the contact angle measured at the calcite-water-toluene interface from the greater calcite surface covered by asphaltene than by resin molecules.

Asphaltenes are the primary species that adsorb on the surface of calcite $\left(\mathrm{CaCO}_{3}\right)^{12}$, in which the most stable cleavage plane is denoted by the (10.4) surface. Accordingly, highly aromatic and polar asphaltenes are thought to be more prone to adsorb through the natural chemical composition in the asphaltene and resin molecules. It is believed that asphaltenes adsorb primarily by interactions between their aromatic and heteroatom groups and the $\mathrm{Ca}^{2+}$ and $\mathrm{CO}_{3}^{2-}$ sites present in the calcite (10.4) surface. This adsorption phenomenon may be associated with the colloidal interactions responsible for the adsorption of nanoaggregates ${ }^{17,18}$. The adsorption processes may also be influenced by organic solvents in crude oil ${ }^{15,23}$.

Computer simulation techniques have been used to study the main molecular representations of nanoaggregates of asphaltenes and resins from their adsorption on the mineral surfaces ${ }^{1,2}$. The adsorption of asphaltenes, resins and their aggregates onto solid surfaces is focused on the understanding of the process phenomenology that leads to the formation of these organic nanoaggregates. This aggregation process in solution could compete with adsorption ${ }^{16}$. In order to simulate natural conditions, we used asphaltenes from water and toluene as solvent and calcite as adsorbent of the rock component.

Our aim is to study at the electronic level, by first-principles calculations with $\mathrm{vdW}$ forces included, the major oil interaction mechanisms between the asphaltene and resin molecules and the surface of $\mathrm{CaCO}_{3}$ as well as the adsorption process of the 
dimers formed. We are interested in evaluating the electrostatic arrangement from the adsorption processes of an isolated molecule and dimer of asphaltene on the calcite surface in the absence of collective effects seen in asphaltene clusters. Therefore, the adsorption mechanisms of these molecules on the surface of minerals can be the basis for understanding a proper chemical mechanism for the different association nanoaggregates of asphaltene and resins molecules on the carbonate rock present in oil reservoirs.

\section{2- COMPUTATIONAL PROCEDURE}

The calcite (10.4) surface with asphaltene and resin models was investigated at the density-functional theory (DFT) ${ }^{24}$ level with the generalized gradient approximation $(\mathrm{GGA})^{25,26}$ implemented in the Quantum Espresso ${ }^{27-29}$ package. We used a plane wave basis set, periodic boundary conditions ${ }^{30}$ and Vanderbilt ultrasoft pseudopotentials ${ }^{31}$. We used here the exchange-correlation functional revised by Perdew, Burke, and Ernzerhof (revPBE) ${ }^{32-34}$. In the revPBE, it is allowed to properly apply vdW density functional (vdW-DF) ${ }^{35-37}$, including dispersion interactions to better describe the long-range vdW forces at the molecule-surface and dimer-surface interfaces.

Calcite bulk is a trigonal crystal system with space group $\mathrm{R} \overline{3} \mathrm{C}$. The $\mathrm{CaCO}_{3}$ structure was built from a hexagonal unit cell with the lattice parameters calculated in $a=b=4.98 \AA, c=17.06 \AA, \alpha=\beta=90.00^{\circ}$ and $\gamma=120.00^{\circ}$. From the cleavage of this structure, the cubic unit cell of area $(2 \times 1)$ was replicated for the adsorption of the asphaltene molecules and the their dimer on the most stable plane (10.4). The lattice parameters were calculated in $a=29.94 \AA, b=23.47 \AA$ and $c=38.63 \AA$. We used the tested vacuum layer with a little more than $30.00 \AA$ to isolate the top of the asphaltene molecules from the bottom of the next calcite layer. The surface was thus represented as a three-layer super-cell (side view in Figure 1A).

Asphaltenes are very complex mixtures. However, in order to make the problem tractable for simulation methods one must assume some representative structures. The asphaltene (Figure 1B) and resin (Figure 1C) models were obtained from the work of Boek et al ${ }^{1}$. They used the Quantitative Molecular Representation (QMR) method to build asphaltene molecules from aromatic, aliphatic groups and 
heteroatoms such as sulfur and nitrogen. Furthermore, these molecules were selected by best match with experimental data, including mass spectroscopy, nuclear magnetic resonance and elemental analysis ${ }^{38,39}$. This approach is widely used in other simulation papers that use the same or similar molecular structures for asphaltenes according the Yen-Mullins model. In particular for the sulfur position, the sulphide group is of potential interest by interacting with the calcite surface to a greater extent than thiophene.

Our calculations were performed with a converged kinetic energy cutoff of $640 \mathrm{eV}$ and charge density of $4,400 \mathrm{eV}$ at the $\Gamma$ point. Based on the trust radius procedure for the Broyden-Fletcher-Goldfarb-Shanno (BFGS) ${ }^{40}$ algorithm, the sites are allowed to relax along the calculated Hellmann-Feynman ${ }^{41}$ forces until residual force components were smaller than $0.05 \mathrm{eV} / \AA$. In the calcite, just the first surface layer is allowed to relax, i.e., all the surface sites displayed in top view in Figure 1A. Thus, the two bottom surface layers are fixed in the bulk positions. Regarding the asphaltene and resin molecules, all the sites are also allowed to relax.

The adsorption energies $E_{1}^{a d s}$ and $E_{2}^{a d s}$ were calculated from the electronic energy differences between the molecule/dimer and the surface $\left(E_{\frac{\text { molecule }}{\text { surface }}}\right.$ or $\left.E_{\frac{\text { dimer }}{\text { surface }}}\right)$ and the pristine surface $\left(E_{\text {surface }}\right)$ and the isolated molecule/dimer ( $E_{\text {molecule }}$ or $\left.E_{\text {dimer }}\right)$ through:

$$
E_{1}^{a d s}=\left(E_{\frac{\text { molecule }}{\text { surface }}}\right)-\left(E_{\text {molecule }}\right)-\left(E_{\text {surface }}\right)
$$

and

$$
E_{2}^{a d s}=\left(E_{\frac{\text { dimer }}{\text { surface }}}\right)-\left(E_{\text {dimer }}\right)-\left(E_{\text {surface }}\right)
$$

The charge density differences at the adsorption interfaces were calculated according to:

$$
\Delta \rho=\rho\left[\frac{\text { molecule }}{\text { surface }}\right]-\rho[\text { molecule }]-\rho[\text { surface }]
$$

and 


$$
\Delta \rho=\rho\left[\frac{\text { dimer }}{\text { surface }}\right]-\rho[\text { dimer }]-\rho[\text { surface }]
$$

where $\rho\left[\frac{\text { molecule }}{\text { surface }}\right], \rho[$ molecule $], \rho[$ surface $], \rho\left[\frac{\text { dimer }}{\text { surface }}\right]$ and $\rho[$ dimer $]$ are respectively the charge densities of asphaltene or resin on calcite, the isolated asphaltene or resin, the isolated calcite surface, dimer on calcite and isolated dimer.

The charge analysis was done by Bader's definition available in the Bader Charge Analysis Code ${ }^{42-45}$, for the following valence electronic configurations for each pseudopotential: $\mathrm{C} 2 s^{2} 2 p^{2}$, Ca $3 s^{2} 4 s^{2} 3 p^{6}, \mathrm{H} 1 s^{1}, \mathrm{~N} 2 s^{2} 2 p^{3}$, O $2 s^{2} 2 p^{4}$ and $\mathrm{S} 3 s^{2} 3 p^{4}$. Then, the charge for each element was obtained by the difference between the calculated Bader charge and number of electrons established at the valence electronic configuration of the pseudopotential cited above. Particularly for nitrogen in resin, it was compared to the charge of this element in the pyridine molecule with the same computational procedure to show the accuracy of the calculated charge.

Electrostatic effects due to periodic boundary conditions in the first-principles quantum-mechanical simulations were calculated in vacuo and in combination with the continuum dielectric environment by the Environ ${ }^{46-48}$ package. From this, it is possible to obtain a better performance with the environment effects, in particular for applications in surface science and materials design from first-principles calculations ${ }^{49-50}$. In these calculations, we used toluene and water with dielectric constants of 2.38 and 80.00 , respectively. In these environment situations, the calculations were done without a new structural relaxation.

\section{3- RESULTS AND DISCUSSION}

Structural optimization was performed using the most stable coordinates of the asphaltene and resin molecules obtained from classical molecular dynamics ${ }^{1}$. As shown in Figure 2 in our first-principles calculations, the average distances for the aromatic and non-aromatic $d \mathrm{C}-\mathrm{C}, d \mathrm{C}-\mathrm{S}$ and $d \mathrm{C}-\mathrm{N}$ bonds and for the $d_{\text {molecule-surface }}$ and $d_{\text {molecule-molecule }}$ interaction distances, and the $\angle \mathrm{C}$-S-C angles were obtained for isolated asphaltene, resin and their dimer, as well as both molecules and their dimer adsorbed on the calcite (10.4) surface, as shown in Table 1. Regarding the $d_{\text {molecule-surface }}$ and 
$d_{\text {molecule-molecule }}$ interaction distances, we used the center of mass of the ring island in the asphaltene and resin molecules.

From molecular dynamics calculations, the potential energy surface for the dimer of resin-asphaltene led to a small number of energetically stable structures derived by the rotation of the resin on the asphaltene molecule. Accordingly, we chose the resin-asphaltene dimer structure shown in Figure 3. The dimer was obtained from previous work with a potential energy surface survey with classical molecular mechanics, using the LAMMPS software ${ }^{51}$. The force field employed was $\mathrm{CHARMM}^{52,53}$. The resin was placed parallel to asphaltene at a distance of $5.00 \AA$. The resin was rotated by $10^{\circ}$ to $350^{\circ}$. Then, the resin was translated by $0.50 \AA$. The same procedure was repeated until $14.00 \AA$. We present complete details regarding this and other sets of structures elsewhere ${ }^{54}$.

In this first analysis, we can observe that the analyzed structural parameters are rather similar in both the studied molecules even after the molecular interaction and surface adsorption. Particularly, the $d_{\text {molecule-surface }}$ distance was the parameter most affected due to the interaction influence onto the aromatic region in the asphaltene and resin molecules and in the dimer on the calcite surface. For the asphaltene and resin molecules, the molecule-surface distances were 6.17 and $4.72 \AA$ respectively. For the dimer, $d_{\text {molecule-surface }}=10.09 \AA$ in the asphaltene-calcite interface. In turn, this increase in the molecule-surface distance is associated through resin-asphaltene interaction with the influence of the resin molecule in the dimer. Although not large, the variation in the $\angle \mathrm{C}$-S-C angles may also show that the chains influence the molecule-molecule interface.

The asphaltene molecule has more aromatic rings and fewer heteroatoms than the resin molecule. According to the calculated Bader charges, there is a charge difference mainly in the aromatic region between the asphaltene and resin molecules, as shown in Table 2. We calculated the sum of square module of the Kohn-Sham states at the bottom of the conduction band, at the lowest unoccupied molecular orbital (LUMO), and at the top of the valence band, at the highest occupied molecular orbital (HOMO), of the studied molecules to analyze the regions related to the energetic levels more easily accessible for the surface and molecular interactions. The aromatic carbon sites are in the more reactive region (Figures $\mathbf{2 A}, \mathbf{B}, \mathbf{C}$ and D), being indeed responsible for the surface adsorption and the formation of the asphaltene and 
resin nano-aggregates on the natural reservoir rock surface. Although the energetic levels more easily accessible are due to the $\pi-\pi$ stacking, this does not eliminate the visible intramolecular contribution from the sulfur sites in LUMO (Figure 2C) and in HOMO (Figure 2D) of resin.

From the projected density of states (PDOS) analysis for the asphaltene and resin (Figure 2E), it is possible to confirm that the sulfur sites display a significant contribution mainly in the valence band of the resin molecule. The aromatic carbon sites are present at the bottom of the conduction band of the asphaltene molecule; although the region of non-aromatic carbons is not adding electronic states at the top of the valence band in both molecules, the energy levels of these carbon sites contribute with the unoccupied states in the resin molecule. Therefore, in addition to the contribution of the aromatic region, the S sites and the carbon chains where these heteroatoms are present can take part in the interaction processes including the resin.

The more energetically stable faces to adsorption of the asphaltene and resin were determined. Then, after the chemisorption of isolated asphaltene and resin on the calcite surface, respectively with adsorption energies of -58.22 and $-35.39 \mathrm{kcal} / \mathrm{mol}$, there is no charge rearrangement in these molecules, as shown for the Bader charges in Table 2. For the charge density calculations in the molecule-surface interfaces, the aromatic rings take part in both surface adsorption processes of the asphaltene (Figure 4A) and resin (Figure 4B) molecules. Particularly in the case of the asphaltene adsorption, even when displaying steric hindrance due the aliphatic chains, there is still an interaction between the region of the aromatic rings and the calcite (10.4) surface. This is energetically more favorably than in the resin-calcite interaction, even though the resin displays less steric hindrance and greater contribution of the $\mathrm{S}$ site in the interaction from the aliphatic chains.

The electrostatic effects with the inclusion of the implicit water (using water dielectric constant) did not show a significant influence on the adsorption energies, being -51.01 and $-29.52 \mathrm{kcal} / \mathrm{mol}$ for the asphaltene-calcite and resin-calcite systems, respectively. In the case of the toluene dielectric constant, this influence is even less marked compared to water $(-50.30$ and $-31.20 \mathrm{kcal} / \mathrm{mol})$. This indicates that the inclusion of water or toluene dielectric environment has a minimal effect toward the surface adsorption processes from the interactions with both aromatic and nonaromatic regions in the asphaltene and resin molecules. 
The electrostatic effects with a correction of dielectric in absence of explicit solvent, which is not so easy to calculate, afford to indicate a possible outside vacuum vulnerability toward the electrostatic arrangement emerged in asphaltene-calcite interaction from a long variation of dielectric constants (toluene and water). Our results are thus important to show the solution electrostatic effects may be indeed somewhat a minor effect for the adsorption of asphaltene on the calcite surface. This proposition is consistent with experimental works related to oil-water interface in presence of toluene ${ }^{55-57}$. In these conditions, the interaction between asphaltene and water tends to be similar to our results found in the asphaltene-calcite interface, which is somewhat experimental difficult/limited to be analyzed due to the complex composition in liquid-solid interfaces. Therefore, we indirectly validated our theoretical results owing to the experimental adsorptive behavior of asphaltene on the water surface. Ruiz-Morales et $a l^{58}$ also obtained similar results from dissipative particle dynamics calculations of asphaltene in the oil-water interface.

In general, the main experimental findings are: the interaction in a parallel way between the region of aromatic rings and the water surface, with aliphatic chains positioned toward the oil bulk where the $\pi-\pi$ stacking is favored, and too high jamming at the oil-water interface by asphaltene monomers leads to asphaltene desorption. This last statement has been particularly concluded from the experimental works of González et $a l^{19,20}$ studying the mineral-water-toluene interface. Here, we showed in a similar way to calcite that the steric hindrance of asphaltene might be overcome through the strong electrostatic attraction between the aromatic region and the surface of the carbonate. Although the initial formation of the nano-aggregate (asphaltene-resin dimer) has favored the $\pi-\pi$ stacking between the aromatic regions rather than the calcite, particular aliphatic chains with heteroatoms (S) may take place to keep the adsorption process on the surface possibly outside of oil bulk with toluene. It would also explain the possible less influence of water molecules over the asphaltene adsorption on the calcite surface due the no interference of the water surface toward the aliphatic groups as seen experimentally ${ }^{55-57}$.

The results of LUMO and HOMO of the asphaltene (Figures 4C and D) and the resin (Figures 4E and F) molecules adsorbed on the surface of calcite ensure that the aromatic region remain accessible for the possible formation of the resinasphaltene agglomerates. From the PDOS results shown in Figure 4G for asphaltene and for resin, the electronic states are more affected in the conduction band region of 
the resin-calcite system, decreasing the available electronic states. Despite being energetically adsorbed on calcite, the resin adsorption process should not lead to further aggregation and therefore the not formation of nano-aggregates because the delocalized LUMO in the resin molecule. This is according to the significant charge density mainly observed in the aliphatic chains and calcite interface after the charge redistribution seen in Figure 4A. Indeed, the difference between the total Bader charges obtained in the aromatic region of the molecules leads preferentially to decreased resin adsorption with respect to the asphaltene molecule.

The next step of our study was to select the molecular dimer formed by asphaltene and resin, so that the adsorption process on the surface of calcite is started with the asphaltene molecule to form the resin-asphaltene-calcite system. The interaction energy in the dimer was found to be similar to the adsorption of the resin on the calcite surface. For the interface in the isolated dimer, LUMO (Figure 3C) and HOMO (Figure 3D) indeed show that $\pi-\pi$ stacking is favored in the molecular interaction between the aromatic regions of the resin and the asphaltene with no effective steric hindrance. This may also lead to the resin chemisorption on the calcite surface, as seen from the charge density mainly present in the resin-calcite interface (Figure 4D). However, it was observed that a significant charge density change in the aliphatic regions occurs in both the molecules, particularly after the their interactions in the dimer (Figure 3A). This indicates that, although the interaction between the asphaltene and resin molecule tends to be mainly by $\pi-\pi$ stacking, there is a possible charge rearrangement induced by the heteroatoms; these sites are not kept in the frontier of the Fermi level, according to PDOS in Figure 3B for the isolated dimer.

Finally compared to adsorption of the asphaltene molecule $(-58.22 \mathrm{kcal} / \mathrm{mol})$, the magnitude of the dimer adsorption energy shows small aggregates may take place on calcite before the growth of the resin-asphaltene interactions on the surface (Figure 5). This can also be concluded from the similar interaction energies between resin-calcite $(-35.39 \mathrm{kcal} / \mathrm{mol})$ and resin-asphaltene $(-25.77 \mathrm{kcal} / \mathrm{mol})$, in which the resin molecule tends to agglomerate with asphaltene molecules in the absence of the calcite influence. Besides increasing the available electronic states in the conduction band, the dimer allows for the formation of more electronic states occupied to the total system affording a possible increase in nano-aggregate on calcite. Taking into account the slightest influence of the correction of dielectric upon adsorption of the isolated molecules, we leave the assumption that it would be even more irrelevant the 
variation of dielectric constants upon the dimer adsorption, in which the $\pi-\pi$ stacking is favored toward to oil bulk ${ }^{58}$.

The charge density at the interface between the resin-asphaltene dimer and the calcite surface is mainly related to the same interactions observed between the aromatic rings and the chain $\mathrm{S}$ in the asphaltene-calcite system (Figure 5A). Particularly, the charge density difference can be seen from calcite to the aromatic rings, while the sulfur in the asphaltene molecule leads to the surface. Furthermore, due the influence of the resin molecule upon the asphaltene molecule previously discussed, the asphaltene molecule also is able to interact by $\pi$ - $\pi$ stacking of the adsorbed dimer, even in the absence of water. Despite the increase in the charge density presence seen in Figure 5A, the LUMO (Figure 5C) and HOMO (Figure 5D) representations display the regions of electronic states related to the asphaltene association and further formation of hemi-micelles on the $\mathrm{CaCO}_{3}$ surface. In both resin and asphaltene (Figure 5B) molecules, the sulfur energetic levels are shifted considerably.

Our aim was to study the implicit solvent effect upon the asphaltenes adsorbed on the surface from the absence of the water-calcite interaction. However, some considerations can be made regarding the possible effect of "real" solvent molecules on surface aggregation. Regarding the value of the adsorption enthalpy of water molecules on the calcite surface, this should be much lower if it is compared to asphaltene adsorption obtained. For example, experimental adsorption enthalpies of ethanol show this molecule is able to displace water from the pure calcite surface ${ }^{59,60}$. Regarding the entropy for the release of solvent molecules upon asphaltene adsorption, Freeman et al. ${ }^{61}$ showed by molecular dynamics (MD) that the adsorption of mannose and methanoic acid molecules are favored by an increase in the entropy due to the displacement of water molecules from explicit solvent on the calcite (10.4) surface.

As a result of the adsorption of the asphaltene molecule and resin-asphaltene dimer, the hydrophilic character of the calcite surface may change to hydrophobic with implications on the system (e.g. reservoir) behavior. The charge of $S$ in the aliphatic chains is different in asphaltene and resin molecules, even before the adsorption. For this reason, we can say that there is a greater rearrangement between the aromatic region and the aliphatic chains (due to $S$ ) in resin, increasing the interaction region on this molecule in the dimer. This could favor the adsorption of 
more nonpolar-molecules with greater influence of solvents, such as toluene. Therefore, small nanoaggregates can adsorb in a way similar to single asphaltene molecules until the $\mathrm{CaCO}_{3}$ surface is fully covered.

\section{4- CONCLUSIONS}

Our simulations are based on first-principles calculations with van der Waals $(\mathrm{vdW})$ inclusion. We showed that the selectivity difference between more polar resin and less polar asphaltene on the $\mathrm{CaCO}_{3}$ (10.4) surface is present in natural reservoir rocks. Due to self-association of nanoaggregates containing resin and asphaltene, the adsorption process of such dimers is important to understand the description of the interactions at the molecular level for the asphaltene association on the calcite surface. Moreover, in order to approach the simulation of natural conditions, we used water and toluene as an implicit solvent, changing the dielectric constant.

The formation of nanoaggregates may be enhanced on the surface compared with the dimer. This leads to further laying of asphaltenes on the surface; higher electronic states available for $\pi-\pi$ stacking interaction are induced by charge rearrangement and are therefore an important consideration for the asphaltene adsorption. Accordingly, the inclusion of water and toluene dielectric environment does not influence the adsorption process, since the dimer is formed on the calcite surface with less influence of the more polar molecules of resin. The influence of the solvent on the resin (mainly on the heteroatoms) may control the formation of the aggregates before interacting with the surface rather than of the growth of the agglomerates on the surface from the asphaltene molecule.

Although there is steric hindering in the interaction of the aromatic ring region on the surface, our results indicate how asphaltene interacts at the particular calcite surface. Therefore, the calcite (10.4) surface can selectively adsorb the asphaltene molecules from oil or model solutions, as a first step in the formation of nanoaggregates. The aliphatic organic chains also are fundamental to the adsorption process, displaying the effect of vdW forces used in our calculations. In parallel, the increase of polarity through the heteroatom content could activate specific portions of the resin molecules, in order to favor the interaction with asphaltene molecules in the agglomerates and the growth of the aggregates on the calcite surface. Future studies 
will look into a wider range of molecular structures for asphaltene and specific effects of functional groups.

\section{5- ACKNOWLEDGEMENTS}

The authors acknowledge the financial support provided by PETROBRAS and the Brazilian agencies Fapesp and CNPq. The computational time for the calculations was provided by the Blue Gene/Q supercomputer support by Research Computing Support Group (Rice University) and High Performance Computing facilities at Universidade de São Paulo. We also acknowledge the computational support of CENAPAD-SP and UFABC supercomputer facilities.

\section{REFERENCES}

[1] T. F. Headen, E. S. Boek and N. T. Skipper, Energy Fuels, 2009, 23, 1220.

[2] T. F. Headen and E. S. Boek, Energy Fuels, 2011, 25, 499.

[3] J. J. Adams, Energy Fuels, 2014, 28, 2831.

[4] O. P. Strausz, T. W. Mojelsky, E. M. Lown, I. Kowalewski and F. Behar, Energy Fuels, 1999, 13, 228.

[5] L. S. Kotlyar, B. D. Sparks, J. R. Woods and K. H. Chung, Energy Fuels, 1999, $13,346$.

[6] O. P. Strausz, A. Morales-Izquierdo, N. Kazmi, D. S. Montgomery, J. D. Payzant, I. Safarik and J. Murgich, Energy Fuels, 2010, 24, 5053.

[7] S. R. Kelemen, C. C. Walters, P. J. Kwiatek, H. Freund, M. Afeworki, M. Sansone, W. A. Lamberti, R. J. Pottorf, H. G. Machel, K. E. Peters and T. Bolin, Geochim. Cosmochim. Ac., 2010, 74, 5305.

[8] T. W. Mojelsky, T. M. Ignasiak, Z. Frakman, D. D. McIntyre, E. M. Lown, D. S. Montgomery and O. P. Strausz, Energy Fuels, 1992, 6, 83.

[9] M. A. Khadim and M. A. Sarbar, J. Petrol. Sci. Eng., 1999, 23, 213.

[10] E. Chouparova, A. Lanzirotti, H. Feng, K. W. Jones, N. Marinkovic, C. Whitson and P. Philp, Energy Fuels, 2004, 18, 1199.

[11] A. K. Golovko, V. F. Kam'yanov and V. D. Ogorodnikov, Russ. Geol. Geophys., 2012, 53, 1374. 
[12] M. Pons-Jiménez, R. Cartas-Rosado, J. M. Martínez-Magadán, R. Oviedo-Roa, R. Cisneros-Dévora, H. I. Beltrán and L. S. Zamudio-Rivera, Colloids and Surfaces A: Physicochem. Eng. Aspects., 2014, 455, 76.

[13] M. A. Anisimov, Y. M. Ganeeva, E. E. Gorodetskii, V. A. Deshabo, V. I. Kosov, V. N. Kuryakov, D. I. Yudin and I. K. Yudin, Energy Fuels, 2014, 28, 6200.

[14] J. Long, Z. Xu and J. H. Masliyah, Langmuir, 2007, 23, 6182.

[15] T. Pernyeszi, A. Patzkó, O. Berkesi and I. Dékány, Colloids and Surfaces A: Physicochem. Eng. Aspects., 1998, 137, 373.

[16] S. Acevedo, M. A. Ranaudo, C. García, J. Castillo, A. Fernández, M. Caetano and S. Goncalvez, Colloids and Surfaces A: Physicochem. Eng. Aspects., 2000, 166, 145.

[17] D. Dudášová, S. Simon, P. V. Hemmingsen and J. Sjoblom, Colloids and Surfaces A: Physicochem. Eng. Aspects., 2008, 317, 1.

[18] D. Dudášová, G. R. Flåten, J. Sjöblom and G. Øye, Colloids and Surfaces A: Physicochem. Eng. Aspects., 2009, 335, 62.

[19] G. González and M. B. C. Moreira, Colloid. Surface, 1991, 58, 293.

[20] G. González and A. Middea, Colloid. Surface, 1988, 33, 217.

[21] J. S. Buckley and J. Wang, J. Petrol. Sci. Eng., 2002, 33, 195.

[22] D. L. Lord and J. S. Buckley, Colloids and Surfaces A: Physicochem. Eng. Aspects., 2002, 206, 531.

[23] A. W. Marczewski and M. Szymula, Colloids and Surfaces A: Physicochem. Eng. Aspects., 2002, 208, 259.

[24] W. Kohn and L. J. Sham, Phys. Rev., 1965, 140, A1133.

[25] M. C. Payne, M. P. Teter, D. C. Allan, T. A. Arias and J. D. Joannopoulos, Rev. Mod. Phys., 1992, 64, 1045.

[26] J. P. Perdew and Y. Wang, Phys. Rev. B, 1992, 45, 13244.

[27] Quantum-ESPRESSO is a community project for high-quality quantumsimulation software, based on density-functional theory. See http://www.quantumespresso.org and http://www.pwscf.org

[28] S, Scandolo, P. Giannozzi, C. Cavazzoni, S. Gironcoli, A. Pasquarello and S. Baroni, Z. Kristallogr., 2005, 220, 574.

[29] P. Giannozzi, S. Baroni, N. Bonini, M. Calandra, R. Car, C. Cavazzoni, D. Ceresoli, G. L. Chiarotti, M. Cococcioni, I. Dabo, A. D. Corso, S. Gironcoli, S. Fabris, G. Fratesi, R. Gebauer, U. Gerstmann, C. Gougoussis, A. Kokalj, M. Lazzeri, 
L. Martin-Samos, N. Marzari, F. Mauri, R. Mazzarello, S. Paolini, A. Pasquarello, L.

Paulatto, C. Sbrac- cia, S. Scandolo, G. Sclauzero, A. P. Seitsonen, A. Smogunov, P. Umari and R. M. Wentzcovitch, J. Phys.: Condens. Matter., 2009, 21, 395502.

[30] G. Makov and M. C. Payne, Phys. Rev. B, 1995, 51, 4014.

[31] D. Vanderbilt, Phys. Rev. B, 1990, 41, 7892.

[32] J. P. Perdew, K. Burke and M. Ernzerhof, Phys. Rev. Lett., 1996, 77, 3865.

[33] J. P. Perdew, K. Burke and M. Ernzerhof, Phys. Rev. B., 1996, 54, 16533.

[34] Y. Zhang and W. Yang, Phys. Rev. Lett., 1998, 80, 890.

[35] M. Dion, H. Rydberg, E. Schröder, D. C. Langreth and B. I. Lundqvist, Phys. Rev. Lett., 2004, 92, 246401.

[36] T. Thonhauser, V. R. Cooper, S. Li, A. Puzder, P. Hyldgaard and D. C. Langreth, Phys. Rev. B, 2007, 76, 125112.

[37] G. Roman-Perez and J. M. Soler, Phys. Rev. Lett., 2009, 103, 096102.

[38] E. S. Boek, D. S. Yakovleva and T. F. Headen, Energy Fuels, 2009, 23, 1209.

[39] H. K. Al Halwachi, D. S. Yakovleva and E. S. Boek, Energy Fuels, 2012, 26, 6177.

[40] S. R. Billeter, A. Curioni and W. Andreoni, Comput. Mater. Sci., 2003, 27, 437.

[41] R. P. Feynman, Phys. Rev., 1939, 56, 340.

[42] W. Tang, E. Sanville and G. Henkelman, J. Phys.: Condens. Matter, 2009, 21, 084204.

[43] E. Sanville, S. D. Kenny, R. Smith and G. Henkelman, J. Comp. Chem., 2007, 28, 899.

[44] G. Henkelman, A. Arnaldsson and H. Jónsson, Comput. Mater. Sci., 2006, 36, 254.

[45] M. Yu and D. R. Trinkle, J. Chem. Phys., 2011, 134, 064111.

[46] O. Andreussi and N. Marzari, Phys. Rev. B, 2014, 90, 245101.

[47] I. Timrov, O. Andreussi, A. Biancardi, N. Marzari and S. Baroni, J. Chem. Phys., 2015, 142, 034111.

[48] http://www.quantum-environment.org/home.html

[49] G. La Penna, C. Hureau, O. Andreussi and P. Faller, J. Phys. Chem. B, 2013, 117, 16455.

[50] A. Fortunelli, W. A. Goddard, Y. Sha, T. H. Yu, L. Sementa, G. Barcaro and O. Andreussi, Angew. Chem. Int. Ed., 2014, 53, 6669.

[51] S. Plimpton, J. Comput. Phys., 1995, 117, 1. 
[52] K. Vanommeslaeghe, E. Hatcher, C. Acharya, S. Kundu, S. Zhong, J. Shim, E. Darian, O. Guvench, P. Lopes, I. Vorobyov, et al. J. Comput. Chem., 2009, 31, 671.

[53] W. Yu, X. He, K. Vanommeslaeghe and A. D. MacKerell, J. Comput. Chem., 2012, 33, 2451.

[54] F. C. D. A. Lima, R. S. Alvim and C. R. Miranda, submitted to Energy Fuels.

[55] J. P. Rane, D. Harbottle, V. Pauchard, A. Couzis and S. Banerjee, Langmuir, 2012, 28, 9986.

[56] J. P. Rane, V. Pauchard, A. Couzis and S. Banerjee, Langmuir, 2013, 29, 4750.

[57] V. Pauchard, J. P. Rane, S. Zarkar, A. Couzis and S. Banerjee, Langmuir, 2014, 30, 8381.

[58] Y. Ruiz-Morales and O. C. Mullins, Energy Fuels, 2015, 29, 1597.

[59] I. S. Pasarín, N. Bovet, M. Glyvradal. M. M. Nielsen, J. Bohr, R. Feidenhans'1 and S. L. S. Stipp, J. Synchrotron Radiat., 2012, 19, 530.

[60] I. S. Pasarín, M. Yang, N. Bovet, M. Glyvradal, M. M. Nielsen, J. Bohr, R. Feidenhans'l and S. L. S. Stipp, Langmuir, 2012, 28, 2545.

[61] C. L. Freeman and J. H. Harding, J. Phys. Chem. C, 2014, 118, 1506. 
(A)

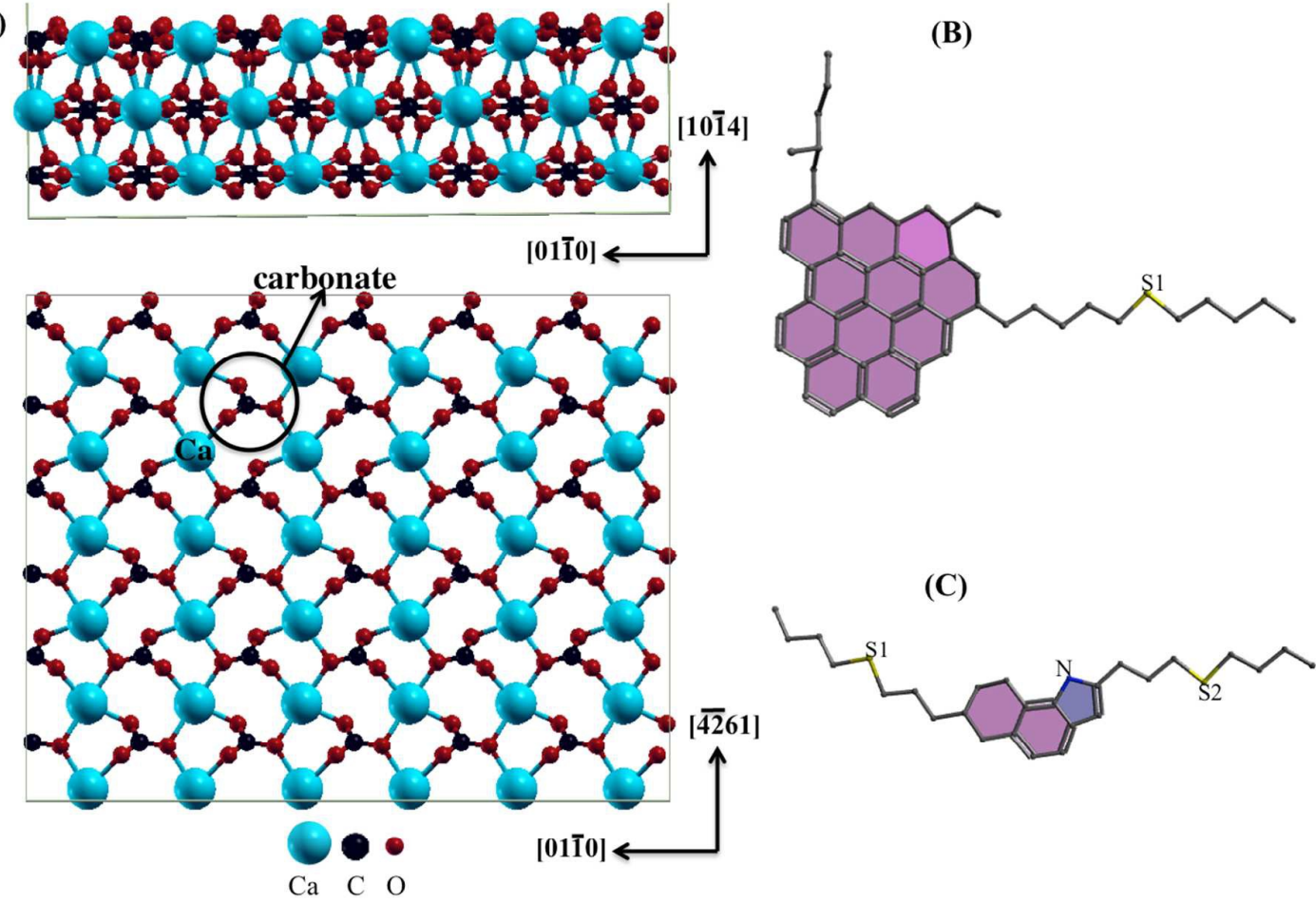

Figure 1: (A) Side and top views of the super-cell of calcite on the surface (10.4). Projections along the of ring region of the molecular models parallel to calcite (10.4) surface (in the absence of hydrogen) of (B) asphaltene and (C) resin models. The five and six-membered rings are light purple and pink, respectively. The sulfur sites are showed as S1 and S2. 


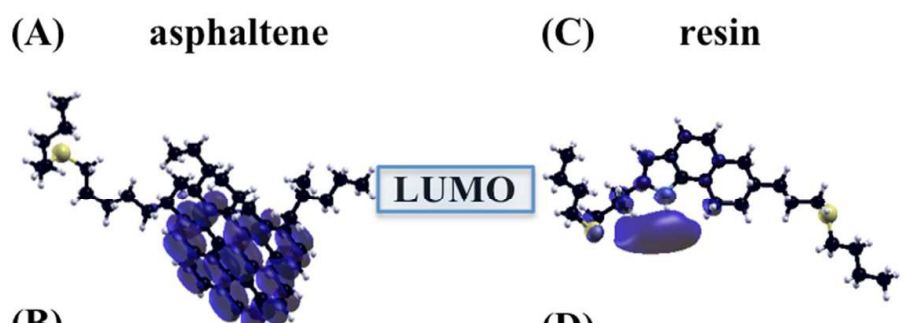

(B)

(D)
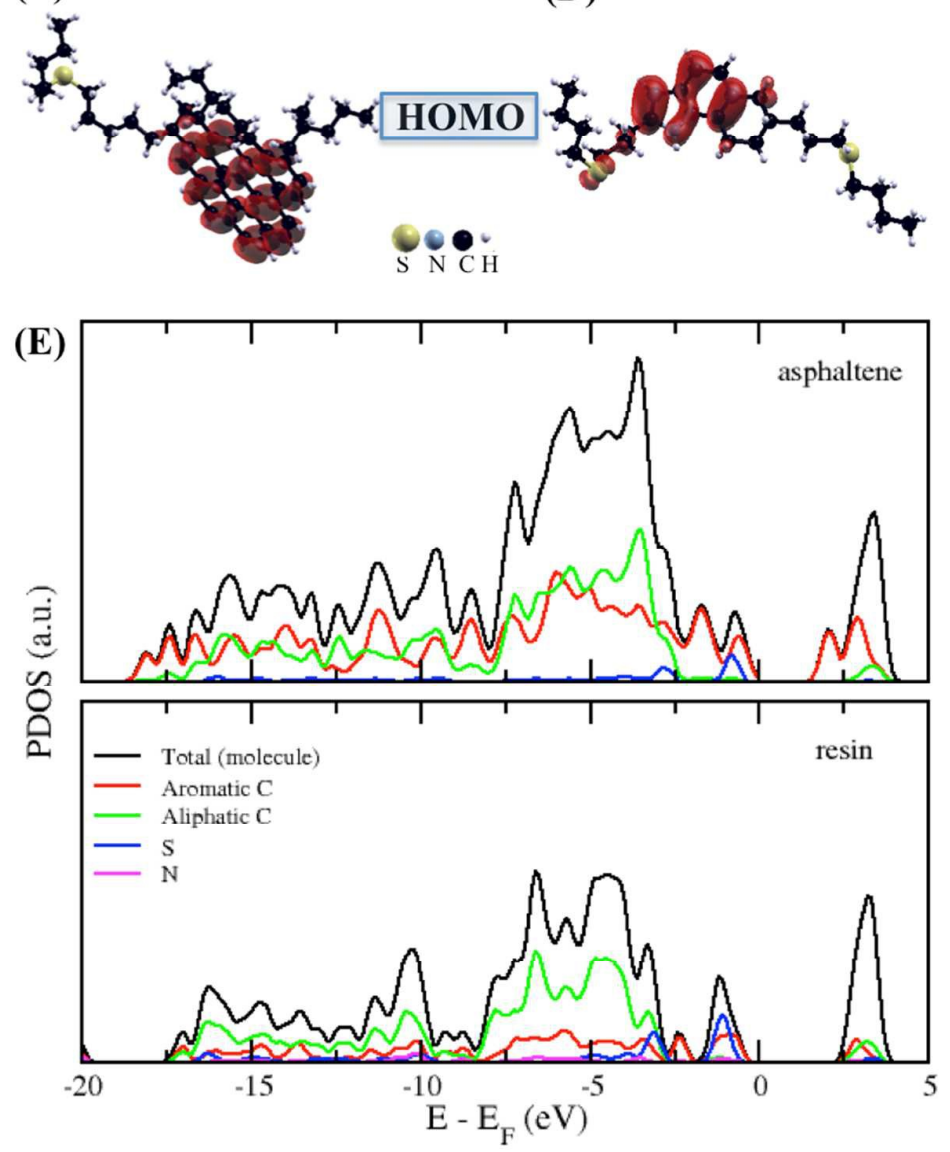

Figure 2: Isolated asphaltene and the resin molecules. Sum of square module of the Kohn Sham states is at the bottom of the conduction band (LUMO) and at the top of the valence band (HOMO). (A) LUMO and (B) HOMO for asphaltene, (C) LUMO and (D) HOMO for resin. Isosurface of -0.0007 to 0.0007 electrons $/ \mathrm{Bohr}^{-3}$. (E) Projected density of states (PDOS) for asphaltene and resin. 


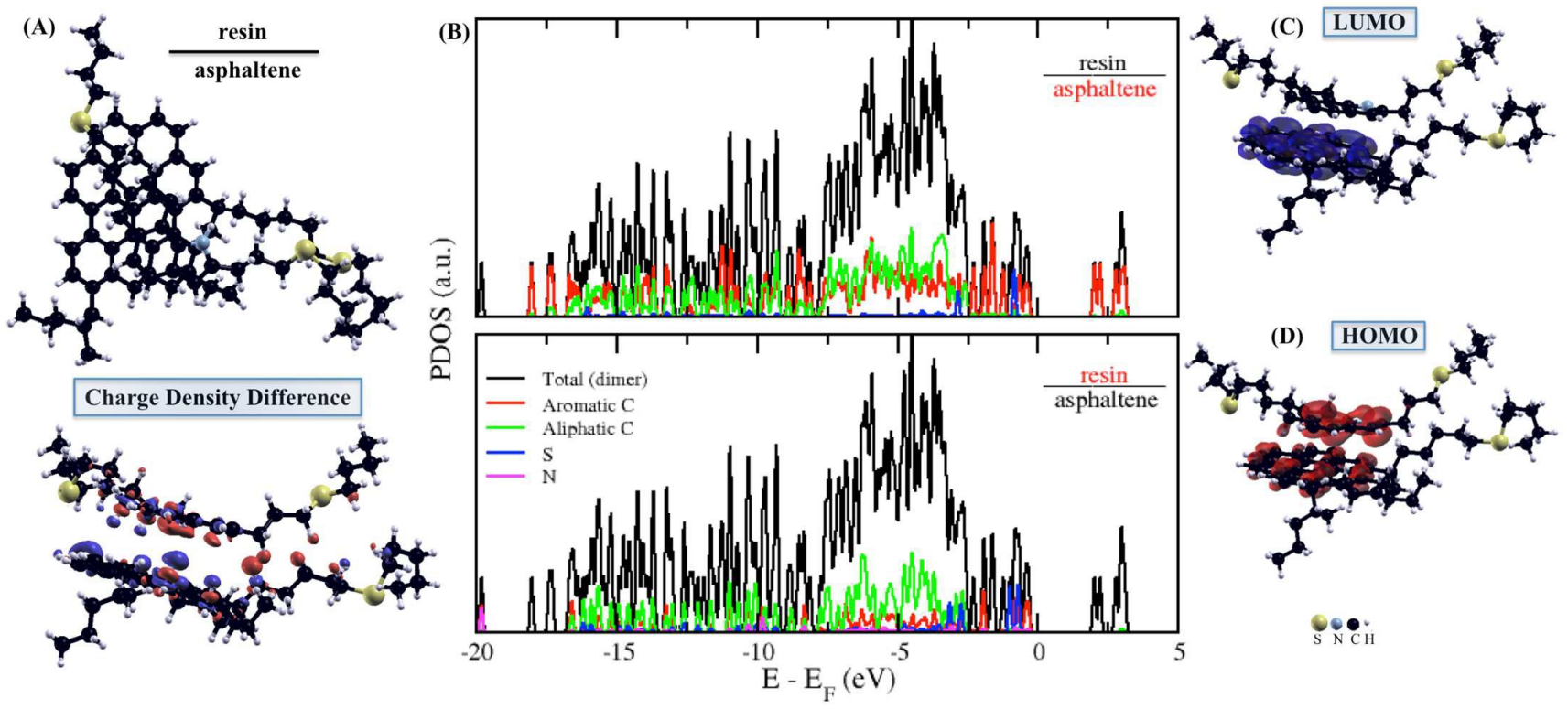

Figure 3: Isolated asphaltene and resin dimer. (A) Top view in up and charge density difference in down for resin-asphaltene. The red and blue colors indicate increase and depletion of charge density, respectively. (B) Projected density of states (PDOS) for resin-asphaltene. Sum of square module of the Kohn Sham states is (C) at the bottom of the conduction band (LUMO) and (D) at the top of the valence band (HOMO) for resin-asphaltene. Isosurface of -0.0007 to 0.0007 electrons $/ \mathrm{Bohr}^{-3}$. 
(A)

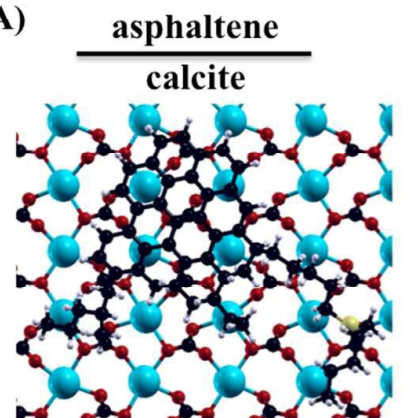

(B)

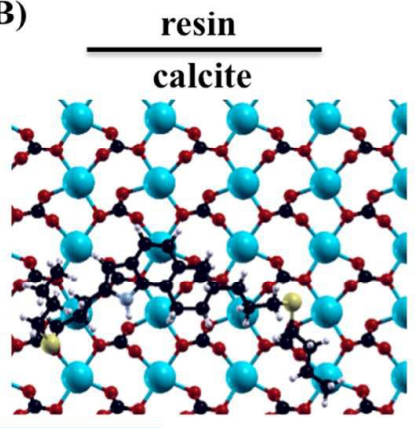

Charge Density Difference

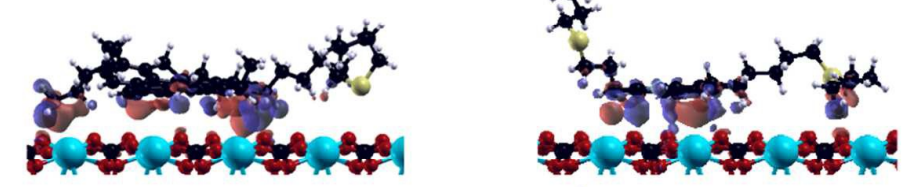

(C)

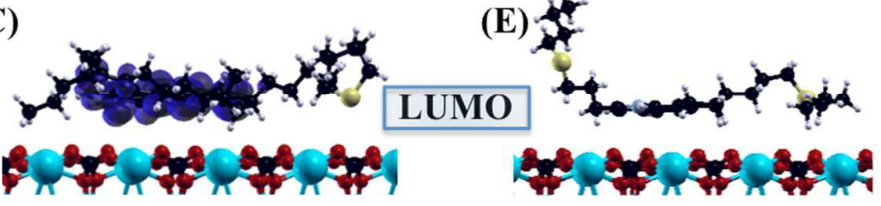

(D)

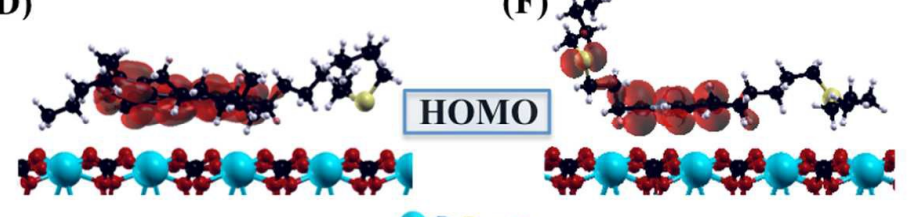

CaN

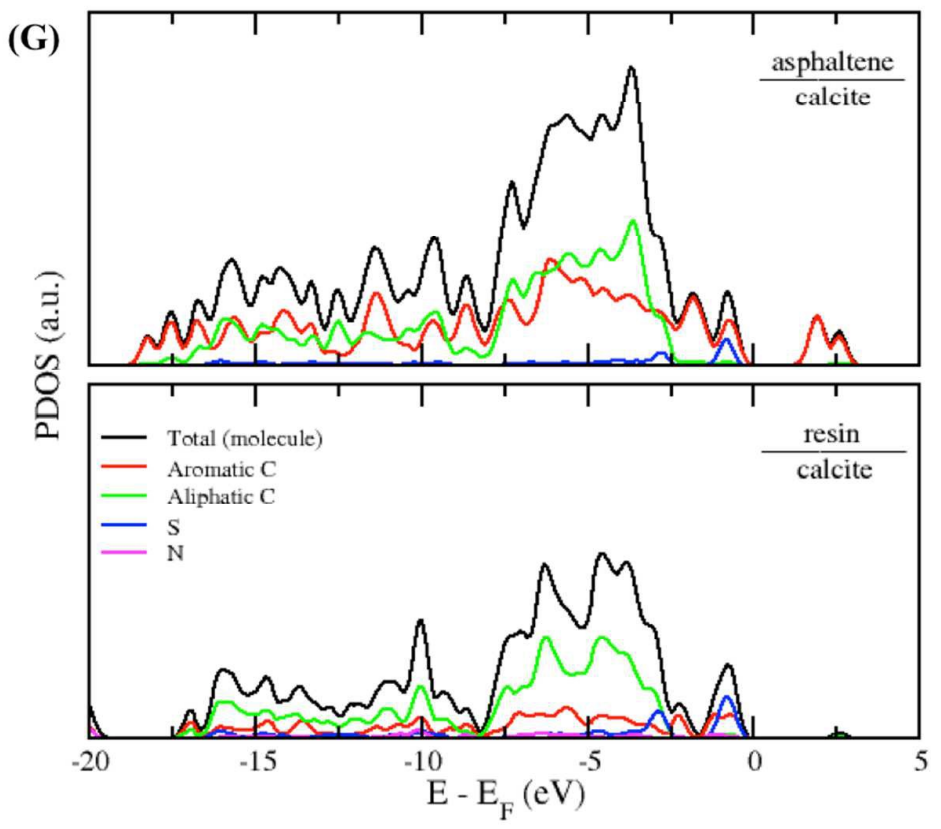


Figure 4: Adsorbed asphaltene and the resin molecules. Top views in up and charge density differences in down for (A) asphaltene-calcite and (B) resin-calcite. The red and blue colors indicate increase and depletion of charge density, respectively. Sum of square module of the Kohn Sham states is at the bottom of the conduction band (LUMO) and at the top of the valence band (HOMO). (C) LUMO and (D) HOMO for asphaltene-calcite, (E) LUMO and (F) HOMO for resin-calcite. Isosurface of -0.0007 to 0.0007 electrons $/ \mathrm{Bohr}^{-3}$. Projected density of states (PDOS) for $(\mathrm{G})$ asphaltene-calcite and resin-calcite.
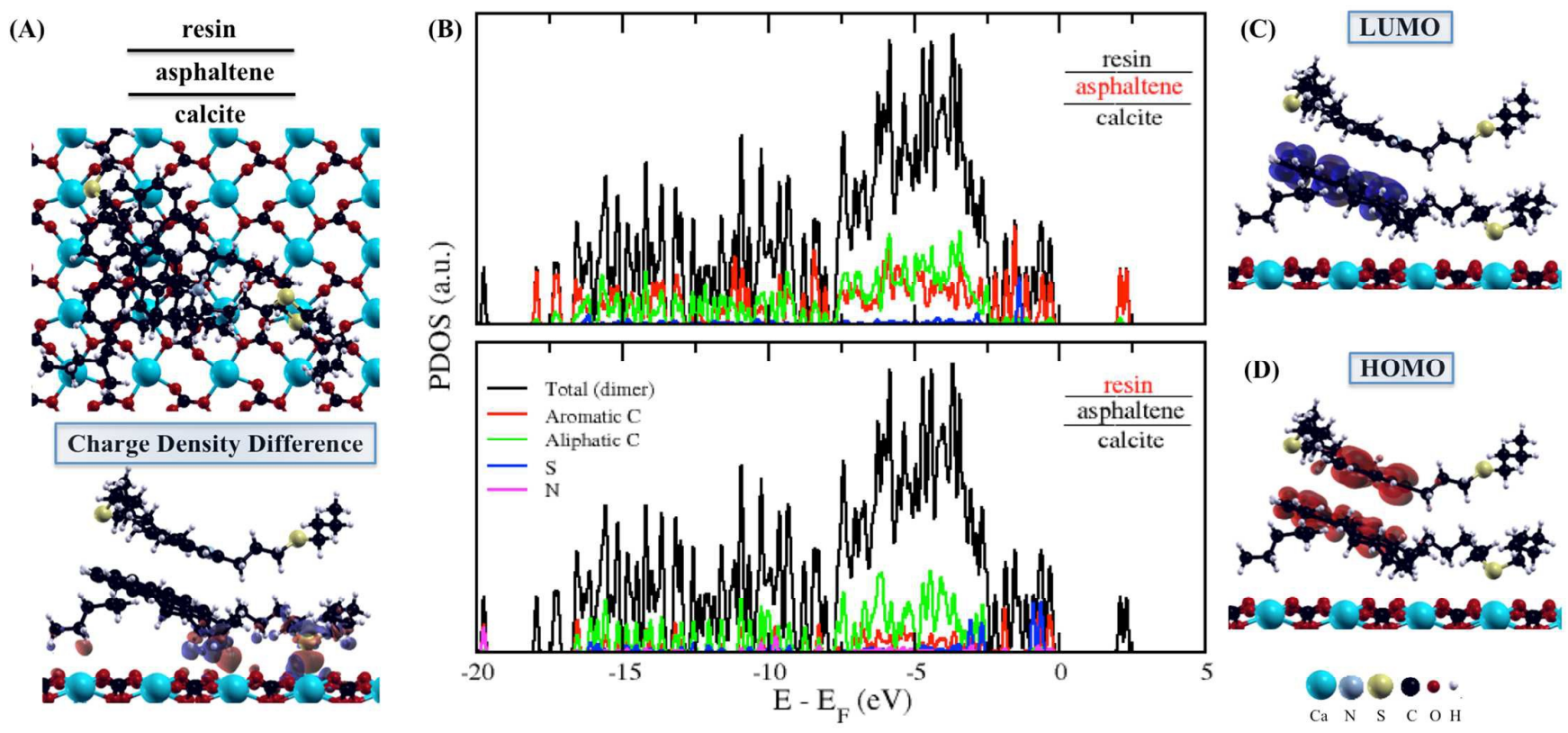

Figure 5: Adsorbed asphaltene and resin dimer. (A) Top view in up and charge density difference in down for resin-asphaltene-calcite. The red and blue colors indicate increase and depletion of charge density, respectively. (B) Projected density of states (PDOS) for asphaltene and resin in resin-asphaltene-calcite. Sum of square module of the Kohn Sham states is at the bottom of the conduction band (LUMO) and at the top of the valence band (HOMO). (C) LUMO and (D) HOMO for resinasphaltene-calcite. Isosurface of -0.0007 to 0.0007 electrons $/ \mathrm{Bohr}^{-3}$. 
Table 1: Structural parameters of distances $(d)$ and angles $(\angle)$ for isolated asphaltene, resin and their dimer, as well as both molecules and their dimer adsorbed on the calcite (10.4) surface. The distances and angles are in $\AA$ and ${ }^{\circ}$, respectively.

\begin{tabular}{|c|c|c|c|c|c|c|c|c|}
\hline \multirow{3}{*}{$\begin{array}{l}\text { Structural } \\
\text { Parameters }\end{array}$} & \multicolumn{4}{|c|}{ Molecules } & \multicolumn{4}{|c|}{ Dimer } \\
\hline & \multirow[t]{2}{*}{ Asphaltene } & \multirow[t]{2}{*}{$\frac{\text { Asphaltene }}{\text { Calcite }}$} & \multirow[t]{2}{*}{ Resin } & \multirow[t]{2}{*}{$\frac{\text { Resin }}{\text { Calcite }}$} & \multicolumn{2}{|c|}{$\frac{\text { Resin }}{\text { Asphaltene }}$} & \multicolumn{2}{|c|}{$\frac{\frac{\text { Resin }}{\text { Asphaltene }}}{\text { Calcite }}$} \\
\hline & & & & & Asphaltene & Resin & Asphaltene & Resin \\
\hline $\begin{array}{c}\text { aromatic } \\
d \mathrm{C}-\mathrm{C}\end{array}$ & 1.42 & 1.43 & 1.41 & 1.41 & 1.47 & 1.41 & 1.42 & 1.41 \\
\hline $\begin{array}{l}\text { aliphatic } \\
d \mathrm{C}-\mathrm{C}\end{array}$ & 1.55 & 1.54 & 1.54 & 1.54 & 1.54 & 1.54 & 1.55 & 1.54 \\
\hline$d \mathrm{C}-\mathrm{S}$ & 1.84 & 1.85 & 1.84 & 1.85 & 1.85 & 1.85 & 1.84 & 1.85 \\
\hline$d \mathrm{C}-\mathrm{N}$ & - & - & 1.40 & 1.40 & - & 1.40 & - & 1.40 \\
\hline$d_{\text {molecule-surface }}$ & - & 6.13 & - & 4.72 & - & - & 10.09 & - \\
\hline$d_{\text {molecule-molecule }}$ & - & - & - & - & 5.45 & 5.45 & 6.19 & 6.19 \\
\hline$\angle \mathrm{C}-\mathrm{S} 1-\mathrm{C}$ & 102.47 & 102.60 & 101.40 & 100.98 & 101.48 & 100.41 & 104.95 & 100.88 \\
\hline$\angle \mathrm{C}-\mathrm{S} 2-\mathrm{C}$ & - & - & 102.80 & 102.90 & - & 100.61 & - & 100.77 \\
\hline
\end{tabular}


Table 2: Charges ( $\left.\mathrm{e}^{-}\right)$obtained by the Bader method for isolated asphaltene, resin and their dimer, as well as both molecules and their dimer adsorbed on the calcite (10.4) surface.

\begin{tabular}{|c|c|c|c|c|c|c|c|c|}
\hline \multirow{3}{*}{$\begin{array}{l}\text { Charge } \\
\text { Region }\end{array}$} & \multicolumn{4}{|c|}{ Molecules } & \multicolumn{4}{|c|}{ Dimer } \\
\hline & \multirow[t]{2}{*}{ Asphaltene } & \multirow{2}{*}{$\frac{\text { Asphaltene }}{\text { Calcite }}$} & \multirow[t]{2}{*}{ Resin } & \multirow{2}{*}{$\frac{\text { Resin }}{\text { Calcite }}$} & \multicolumn{2}{|c|}{$\frac{\text { Resin }}{\text { Asphaltene }}$} & \multicolumn{2}{|c|}{$\frac{\frac{\text { Resin }}{\text { Asphaltene }}}{\text { Calcite }}$} \\
\hline & & & & & Asphaltene & Resin & Asphaltene & Resin \\
\hline$\underset{\mathrm{C}}{\operatorname{aromatic}}$ & -0.01 & -0.01 & 0.20 & 0.19 & -0.01 & 0.21 & -0.01 & 0.22 \\
\hline $\begin{array}{c}\text { aliphatic } \\
\text { C }\end{array}$ & 0.07 & 0.06 & 0.07 & 0.05 & 0.06 & 0.05 & 0.06 & 0.05 \\
\hline $\mathrm{S}$ & -0.10 & -0.10 & -0.06 & -0.05 & -0.06 & -0.06 & -0.10 & -0.06 \\
\hline $\mathrm{N}^{*}$ & - & - & -2.24 & -2.19 & - & -2.24 & - & -2.29 \\
\hline
\end{tabular}

*The nitrogen charge in resin is similar to one calculated for the pyridine molecule (2.83).

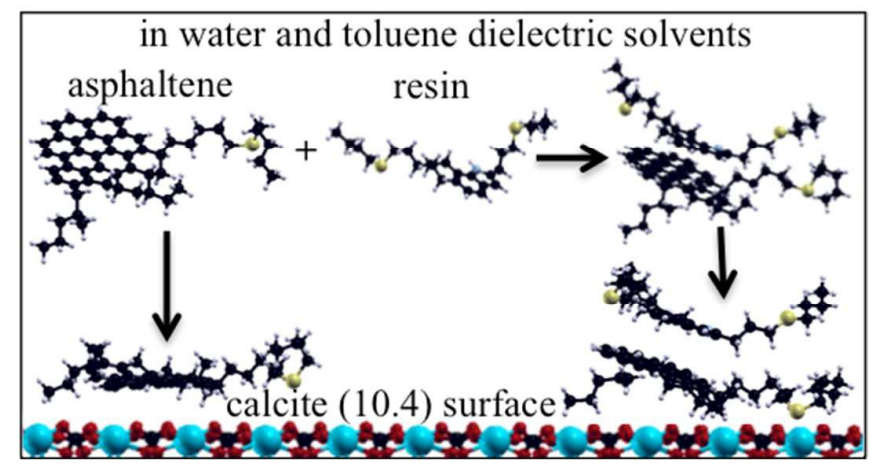

